\title{
Comet Halley: A Media Event
}

\section{Jean-Louis Heudier}

Téléscope de Schmidt, CERGA, Caussols, F-06460 St. Vallier de Thiey, France

Comet P/Halley's life as a "media event" started long ago, because the first use of communication (in the modern sense of the term) goes back to Rabelais, who published in Patagrueline Prognostication pour l'an 1532:

"And whyth the comete sene laste yeare and the retrograte of Saturne a greate skoundrell shalle die, all weazynge and courd in scabbes, in the hospitall, and at his death there will be horrible warre between cattes and rattes, dogges and hares, faulcons and duckes, monkes and egges."

Since then ways of spreading ideas have progressed enormously, but comets have remained "fashionable" and each of the last six apparitions of P/Halley has been the occasion of outbursts that are far removed from the scientific view.

What appears important is that the cometary phenomenon is so easily used by the media. The spectacular and unexpected nature of apparitions are partly the cause, but the cultural impact of comets that have punctuated history also seems necessary to explain the persistence of fanciful ideas. Comets, despite scientific progress, have retained their mysterious, sacred and supernatural nature. You only have to glance through contemporary press cuttings of the most spectacular apparitions to be convinced of that. Nothing has changed from ancient fears. Contrary to what Alain ${ }^{1}$ hoped at the beginning of the century, the "marvel" has not yet become a "tangible thing". People nowadays still like to frighten themselves, just as they did thousands of years ago. Did not Gassendi, three centuries ago, write:

"Yes, comets are frightening, but only because of our foolishness. We make our own objects of fear, and, not content with real ills, we acquire imaginary ones."

Exploitation of comets has progressively changed and we tend to laugh at the things that people frightened themselves with, but often the laugh is rather forced. Comets remain interesting and worrying because they have retained some of that mystery that mankind revels in. Over the course of centuries comets have caused fear for completely opposing reasons: at first because no-one knew what they were, and then because their movement and their composition was understood. The fear remains, only its cause has altered. And fear has always been an instrument of power. Fear is fed by ignorance: maintaining ignorance creates dependence and hence power.

\footnotetext{
${ }^{1}$ Emile Chartier, known as Alain, (1868-1951), French philosopher - Eds.
} 
Helped by progress in communications, the phenomenon grew in a spectacular fashion in 1910, and with this first apparition in the 20th century, we can truly speak of "media manipulation". The comet was used in the very typical "small ads" of the time. Products connected with the event began to be sold: books, songs, postcards, gas masks, and "anti-comet" pills. Illustrations even appeared predicting trips to the comet. The phenomenon is important and Alain makes one of his most significant remarks about it.

"I can imagine what a historian one hundred years from now will write about the Great Terror of 1910. I can see him searching in our newspapers for everything that bears upon the comet. The very collection of documents about the same event will be in itself an error, because he would see remarks about the comet separated from everything else and forming their own little world. Naturally he will not pay attention to the ordinary, rational, way of life that does nevertheless go on around, and amongst, us, as everyone can see. Chroniclers only note what is strange and outside the ordinary. A six-page paper that wanted to leave future historians with an exact picture of human life on one day would have to fill its columns with: "People worked, drank, ate, slept; everyone thought about their own concerns and loves; there were births, deaths, illnesses, and follies, just like every year at this time. All's well." In such a description, and giving everything the space that is its due, doubtless the newspaper would not have a single line about all the crimes, extravagances and panics. Because humanity is wonderfully wise, and has perhaps always been; but the historian, perforce, sees it as mad, stupid, or bloody."

The press, by its very nature, greatly amplifies the real impact of comets. This impact is changed and exaggerated yet again by historians. We may ask how our own attitude during this last apparition will be regarded by our descendants in 2061 . What is certain is that progress in communications since 1910 has widened the gap between the public's real attitude and the image given by the press. With all this "progress" the 1986 apparition just had to be the subject of media excesses: and it was.

Each of the latest passages of $\mathrm{P} /$ Halley has been the occasion of scientific "firsts", and the 1986 one was no exception: first electronic recovery, first space rendezvous, etc. The press therefore had a whole range of subjects with which to fill its columns, and it did not let the opportunity pass. Every paper in every country used the comet at least once to waste ink and paper. Thanks to all this clamour, new sales opportunities were created: special flights allowed people to (faintly) see the comet; cruises took astronomers and the curious to discover the sky; objects of all sorts were sold: the media event became a commercial event. Never have so many small telescopes been sold, and doubtless never have so many people looked at the sky: quite apart from proper scientific work, we can be quite certain that in the last few years there have been more people curious about the sky, and more telescopes pointed at the comet than over the whole course of astronomical observation.

Should we despair over such banal exploitation of a scientific event? Personally, I think not. I believe instead that de-facto situation ought to be used to reflect science in general, and astronomy in particular. If such excesses are possible, it is only 
because we have not known, or have not wanted to know, how to use the possibilities offered by modern means of communication. If astronomers left the field wide open for sellers of gadgets and such-like amateurs to exploit, it was because they did not realise that they ought to play a part in promoting understanding, and that that part had been considerably eased by past cultural changes caused by various apparitions of comets, and particularly by P/Halley. And science gained from the press taking up the event, from people talking about comets, from numerous books having been written, and from the comet having been "sold" in every conceivable fashion. It is a pity that astronomers did not know how to use effectively the tool formed by the media in this last quarter of the 20th century. Let us hope that our descendants in 2061 will be better at it than us; but don't let's fool ourselves: the history of recent apparitions of $\mathrm{P} / \mathrm{Halley}$ has shown that mankind has difficulty in escaping from its fantasies: comets, and $\mathrm{P} / \mathrm{Halley}$ in particular, are just one of many. When the public no longer reacts to comets, and apparitions have become just a common-place event for nearly everyone, the wonder will have vanished and knowledge will have reached a limit. We have not yet reached that point, and here in a country where more than one person in three thinks that the Sun revolves around the Earth, selling the comet, fear, and astrology remains a normal part of life. Astronomers will have carried out their duty when it becomes impossible to say just anything, just anywhere, and just when the media like, about objects that astronomers have studied for thousands of years. The "media event" will have become just part of general scientific knowledge, and finally it will be possible to satisfy Arago, who in 1835 said:

"Listen for just a moment to the long addresses made about the future comet and then decide whether we can really be proud of this supposed diffusion of knowledge."

It was Alain, the worthy witness of the 1910 event, who best expressed the change in Man's attitude to the phenomenon:

"Ten centuries ago, as soon as a comet appeared, nearly everyone acted as if they were mad. They expected terrifying events and the collapse of everything. In this they did not think that they were mad, but on the contrary, very sensible. We must remember that for them the regular movement of the stars was the greatest expression of the essential order underlying the world, the apparition of a comet was already a breakdown of that order.

Institutions had to achieve a certain stability and continuity for common sense to acquire its own doctrine, and for the universe gradually to come to be seen as being free from miracles. Consider Halley's Comet and what a number of consistent observations and calculations agreeing with observations were needed to change it from a marvel into a mundane object. Halley, Clairault, Pingré and Pontécoulant, needed not only highly involved methods of calculation, but also the leisure, the security, and the baker at the door every morning. This, friends, is how we all, each in our own way, contribute to building common wisdom, that finally traces the orbits of comets and finally explains the miracle. I can picture a fine new myth: that of Concord chasing away the Gods."

The media clamour that we have just experienced shows that common sense has not yet reached that stage, and that Man still seeks miracles. 